\title{
Changes in the bispectral index and cerebral oxygen saturation during neuroendovascular intervention under general anesthesia
}

\author{
Seong-Soo Choi, Jin-Seok Kim, In-Kyung Park, Gun Lee, and Kyung-Don Hahm \\ Department of Anesthesiology and Pain Medicine, Asan Medical Center, University of Ulsan College of Medicine, Seoul, Korea
}

Neuroendovascular interventions using coil embolization, stent insertion, or balloon-expander techniques are currently employed to treat intracranial aneurysms, arteriovenous malformations (AVMs), and cerebrovascular stenosis or occlusion. Several complications may occur during neurointervention, including rupture of vessels, vasospasm, thromboembolism, or catheter malposition. Techniques used to monitor complications associated with neurointervention include neurologic examination, electroencephalography (EEG), motor- and somatosensory-evoked potentials, assessment of transjugular oxygen saturation, transcranial Doppler ultrasound monitoring, and measurement of cerebral oxygen saturation. Although the application and utility of near-infrared cerebral oxymetry during neuroendovascular intervention have been evaluated [1-3], statistical analysis was lacking and relatively small numbers of patients were studied.

The bispectral index (BIS) is a complex parameter calculated from several EEG-derived sub-parameters, including the relative beta ratio, high-order bispectrum, and the burst suppression ratio. BIS has been widely used to evaluate sedative-hypnotic status during surgery under general anesthesia. However, to the best of our knowledge, no previous study has examined changes in BIS values during neurointerventions.

Thus, the aim of the present study was to assess changes in BIS and regional cerebral oxygen saturation $\left(\mathrm{rSO}_{2}\right)$ using near-infrared spectroscopy (NIRS) in anesthetized patients undergoing neuroendovascular interventions.
This study was approved by our Institutional Review Board prior to study commencement. After written informed consent had been obtained from each patient or parents of adolescent patient, 28 patients (male 12, female 16), aged $14-81$ years (mean $50.9 \pm 14.3$ ), undergoing elective neuroendovascular procedures conducted by neurointerventionists were enrolled in the study. Patients were diagnosed with cerebral aneurysms $(n=17)$, cerebral vascular stenosis $(n=2)$, AVMs $(n=8)$, or carotid tumor $(\mathrm{n}=1)$. A BIS sensor and two cerebral oxymeter sensors were placed on the forehead of each patient to provide continuous and simultaneous monitoring of BIS and $\mathrm{rSO}_{2}$. General anesthesia was induced with target-controlled infusion (TCI) of propofol $3.0 \mu \mathrm{g} / \mathrm{ml}$, remifentanil $5.0 \mathrm{ng} / \mathrm{ml}$, and a bolus injection of $50 \mathrm{mg}$ atracurium. Anesthesia was maintained with air $(1.5 \mathrm{~L} / \mathrm{min})$ and oxygen $(1 \mathrm{~L} / \mathrm{min})$, intermittent bolus injections of atracurium, and continuous infusion of propofol $(2.0-3.0 \mu \mathrm{g} / \mathrm{ml})$ and remifentanil $(3.0-5.0 \mathrm{ng} / \mathrm{ml})$.

Hemodynamic, BIS, and $\mathrm{rSO}_{2}$ values were obtained immediately before and after, and 5 min after, neuroendovascular intervention (either embolization or stent insertion). The TCI rates of propofol and remifentanil did not change over this interval. All data are presented as means \pm standard deviations. Statistical analysis was performed using SPSS version 12 (SPSS Inc., Chicago, IL, USA). All continuous parameters studied were evaluated using repeated measures analysis of variance. For all comparisons, a $\mathrm{P}$ value less than 0.05 was considered to be statistically significant.

Corresponding author: Kyung-Don Hahm, M.D., Ph.D., Department of Anesthesiology and Pain Medicine, Asan Medical Center, University of Ulsan College of Medicine, 388-1, Pungnap 2-dong, Songpa-gu, Seoul 138-736, Korea. Tel: 82-2-3010-5979, Fax: 82-2-3010-6790, E-mail: kdhahm@amc.seoul.kr

(c) This is an open-access article distributed under the terms of the Creative Commons Attribution Non-Commercial License (http:// creativecommons.org/licenses/by-nc/3.0/), which permits unrestricted non-commercial use, distribution, and reproduction in any medium, provided the original work is properly cited. 
There were no significant hemodynamic differences immediately before, immediately after, or 5 min after commencement of intervention except for mean arterial blood pressure 5 min after intervention (Table 1). The BIS value was increased significantly 5 min after intervention compared to preintervention values $(\mathrm{P}<0.05)$. The hemisphere ipsilateral to the lesion in patients under general anesthesia showed a significant increase in $\mathrm{rSO}_{2}$ both immediately and 5 min after intervention $(\mathrm{P}<0.05)$. Interestingly, the $\mathrm{rSO}_{2}$ value in the side contralateral to the lesion in patients under general anesthesia was also increased significantly 5 min after intervention $(\mathrm{P}<$ 0.05).

The primary positive finding of this study was that, in patients under general anesthesia, the BIS value was increased $5 \mathrm{~min}$ after neurointervention without any concomitant significant hemodynamic change. Thus, changes in cerebral blood flow caused by an intervention may affect cerebral electrical activity. Our results suggest that cerebral electrical activity may increase, or at least, may not disturb after neuroendovascular embolization or stent insertion.

In the present study, total intravascular anesthesia with TCI of propofol and remifentanil was used during neuroendovascular procedures. EEG signal output and BIS can both be affected by propofol and remifentanil, in a dose-dependent manner [4]. Therefore, the TCI rates of propofol and remifentanil were not varied from immediately before neurointervention to at least $5 \mathrm{~min}$ after neurointervention, to exclude any effect of anesthetic drugs on the parameters measured. Both propofol and remifentanil concentrations did not affect the changes of hemodynamics, $\mathrm{BIS}$ and $\mathrm{rSO}_{2}$ values significantly.

Kuroda et al. [5] found that NIRS was useful to evaluate the state of cerebral oxygenation continuously during carotid surgery and could be a more sensitive measure to detect ischemic crisis than other indirect methods for measuring regional cerebral blood flow. Also, it has been reported that acute and persistent decreases in oxygen saturation were associated with vascular complications arising in the course of neuroendovascular procedures, and were detectable before development of clinical symptoms [2,3]. In the present study, the $\mathrm{rSO}_{2}$ values in patients under general anesthesia were not altered significantly after neuroendovascular intervention. Interestingly, the mean $\mathrm{rSO}_{2}$ value of the side contralateral to the lesion in patients under general anesthesia increased 5 min after intervention. This may be attributed to restoration of cerebral blood flow influenced the well-developed collateral circulation.

One of limitations of NIRS and BIS is that the BIS as well as $\mathrm{rSO}_{2}$ values only indicate the alterations of frontal area of the brain. Therefore, our results may not be adequate to reflect on the exact changes of whole cerebral perfusion before and after neurointervention. In addition, it is well known that cerebral perfusion was altered by arterial partial $\mathrm{CO}_{2}$ pressure $\left(\mathrm{PaCO}_{2}\right)$. Although we did not evaluate the exact levels of $\mathrm{PaCO}_{2}$, patients were maintained end-tidal $\mathrm{CO}_{2}$ values in the range of 30-35 mmHg during the procedure in the present study. Another limitation is the relatively lack of consistency for patient selection. Although we could not rule out that the disease-specific intervention may affect the cerebral electrical activity and/or cerebral blood flow, all patients included in this study were conducted the embolization or stent insertion which aimed at the adequate restoration of cerebral perfusion. In conclusion, both BIS and the $\mathrm{rSO}_{2}$ values were increased, or at least were not altered after neuroendovascular intervention without significant hemodynamic change in anesthetized patients. These results indicate that both cerebral electrical activity and cerebral blood flow increase immediately after neuroendovascular intervention in anesthetized patients.

\section{Acknowledgements}

The authors thank Dr. Seong-Sik Cho, M.D. (Health Care Center, Incheon Worker's Compensation Insurance Hospital, Incheon, South Korea) for his kind advice on the statistical procedures employed in this study.

Table 1. Hemodynamic Parameters, BIS and Regional Cerebral Oxygen Saturation (\%) During Neuroendovascular Intervention (n = 28)

\begin{tabular}{lccc}
\hline & Immediately before intervention & Immediately after intervention & 5 min after intervention \\
\hline Heart rate (bpm) & $57.2 \pm 7.4$ & $56.4 \pm 7.1$ & $56.7 \pm 7.0$ \\
Systolic BP (mmHg) & $108.7 \pm 12.0$ & $109.6 \pm 10.6$ & $112.0 \pm 11.7$ \\
Diastolic BP (mmHg) & $59.9 \pm 7.6$ & $60.2 \pm 6.5$ & $71.9 \pm 7.2$ \\
Mean BP (mmHg) & $77.5 \pm 9.1$ & $78.1 \pm 8.2$ & $79.8 \pm 7.8^{*}$ \\
$\mathrm{BIS}$ & $44.2 \pm 7.9$ & $44.5 \pm 9.5$ & $48.8 \pm 10.2^{*}$ \\
$\mathrm{rSO}_{2}$ (ipsi) (\%) & $63.1 \pm 8.4$ & $64.4 \pm 8.0^{*}$ & $65.3 \pm 8.3^{*}$ \\
$\mathrm{rSO}_{2}$ (contra) (\%) & $64.6 \pm 10.6$ & $65.1 \pm 10.4$ & $65.8 \pm 10.1^{*}$ \\
\hline
\end{tabular}

Values are means \pm SDs. BP: blood pressure, bpm: beats per minute, BIS: bispectral index, $\mathrm{rSO}_{2}$ : regional cerebral oxygen saturation, ipsi: ipsilateral with respect to lesion side, contra: contralateral with respect to lesion side. ${ }^{*}$ A significant difference compared to the value prior to intervention $(\mathrm{P}<0.05)$. 


\section{References}

1. Bhatia R, Hampton T, Malde S, Kandala NB, Muammar M, Deasy $\mathrm{N}$, et al. The application of near-infrared oximetry to cerebral monitoring during aneurysm embolization: a comparison with intraprocedural angiography. J Neurosurg Anesthesiol 2007; 19: 97104.

2. Hernandez-Avila G, Dujovny M, Slavin KV, Luer MS, Nijensohn E, Geremia G, et al. Use of transcranial cerebral oximetry to monitor regional cerebral oxygen saturation during neuroendovascular procedures. AJNR Am J Neuroradiol 1995; 16: 1618-25.

3. Schwarz G, Litscher G, Delgado PA, Klein GE. An NIRS matrix for detecting and correcting cerebral oxygen desaturation events during surgery and neuroendovascular procedures. Neurol Res 2005; 27 : 423-8.

4. Bouillon TW, Bruhn J, Radulescu L, Andresen C, Shafer TJ, Cohane $\mathrm{C}$, et al. Pharmacodynamic interaction between propofol and remifentanil regarding hypnosis, tolerance of laryngoscopy, bispectral index, and electroencephalographic approximate entropy. Anesthesiology 2004; 100: 1353-72.

5. Kuroda S, Houkin K, Abe H, Hoshi Y, Tamura M. Near-infrared monitoring of cerebral oxygenation state during carotid endarterectomy. Surg Neurol 1996; 45: 450-8. 